\title{
New Product Opportunity Identification: A Perspective from Inside the Intuitive Phenomenon
}

\author{
Josmael Roberto Kampa ${ }^{1 *}$, Carlos Cziulik', Paulo André de Camargo Beltrão
}

\begin{abstract}
Innovating comprises generating offers that make the preexisting ones obsolete. It implies in the creation or recognition of new forms of differentiation, the Opportunities Identification (OI). These may be due, among others, to new solutions or new problems to be solved, the latter a less explored path in the Product Development Process. There are studies aimed at systematizing OI, but present a discreet behavior in front of intuitive approaches. These rely on individual talent, a non-unanimous resource. As innovation is time-sensitive, there is room for artificial stimuli to intuition, which relies on the need for a close understanding of the phenomenon. This paper presents the descriptive research outcomes from a broader prescriptive study, which adopted the Design Research Methodology structure. Because OI is primarily a cognitive process and difficult to observe by a third party, one of the researchers submitted himself to the experience and recording of the phenomenon. The experience constitutes a unique case of OI accompanied during 2590 days. During this time, the study recorded 137 potential opportunities (units of analysis) by serendipity. Through the interpretation of the experienced phenomenon, the results comprise three perspectives: i/to the interaction of influence factors pointed out in the literature; ii/to the opportunities emergence; and, iii/to the opportunities identification. It is evident the challenge of considering opportunities as problems by its tendency of incubation. The work presents new research questions, hypotheses, and explanations valid to the case that potentially stimulate new exploratory or confirmatory researches or both.
\end{abstract}

Keywords: opportunity identification; opportunity recognition; opportunity creation; front end of innovation; new product development process.

Submitted: March 21 $1^{\text {st }}, 2020$ / Approved: May $13^{\text {th }}, 2020$

\section{Introduction}

In order to innovate, it is necessary to recognize or create new unprecedented forms of differentiation. It requires the existence of individuals with unique opportunity identification (OI) ability, who can recognize or create chances of gains by offering an original value in an exchange process. Being this competence mostly cognitive, it presents itself as a challenge when it comes to its explicitness and transmission.

George et al. (2016) comment that research on how individuals recognize opportunities represents a key topic in a fragmented and poorly developed field. Some studies seek to describe how the models of the natural/sociocultural phenomenon occur (Ko, 2004; Fiet, Clouse and Norton Junior, 2004; George et al., 2016, among others). Furthermore, others whose purpose is to prescribe artificial models for improvement (Urban and Hauser, 1993; Cooper, 2001 and 2017; Koen et al., 2002; Cooper and Edgett, 2007; Fiet, 2007; Kelley and Littman, 2007; Stull, Myers and Scott, 2008; Kim and Mauborgne, 2015 and 2017, among others). The OI is a multidisciplinary topic that requires dialogue between different areas of knowledge. Moreover, about the nature of the identified object, whether opportunities to develop new offerings (products, services, experiences) or new supply capacity (business models) or both.

In the domain of entrepreneurship, the theory about OI is vast, especially on the factors that influence the process (Ardichvili, Cardozo and Ray, 2003; Butler, 2004; Baron and Shane, 2007; George et al., 2016). However, it still reserves fundamental conflicts regarding the recognition or creation of opportunities. Vaghely and Julien (2010) establish that cognitivists use formal models or algorithms to recognize opportunities, and constructionists use interpretive or heuristic models to construct them. De Jong and Marsili (2015), addressing Schumpeter's $(1934,1942)$ and Kirzner's (1973) views, argue that in practice, there is no excluding division. However, studies such as those carried out by Ramoglou and Zyglidopoulos (2015), Foss and Klein (2017), Alvarez et al. (2017), Ramoglou and Tsang (2016, 2017a and 2017b), Berglung and Korsgaard (2017), Davidsson (2017a, 2017b, 2017c) and Wood (2017a and 2017b) still discuss the topic with conflicting outcomes. Perhaps, like Hansen, Monlor, and Shrader (2016) comment, the aggravating factor is the lack of clarity of the opportunity construct. Kitching and Rouse (2017) even suggest abandoning it and thinking from other ontological perspectives. The view of opportunity as a particular problem is one of particular interest in this study.

From the specific perspective of the Product Development Process (PDP), there is a predominant OI focus on the creation of new solutions. The ideation composes the initial activities of the Front End of Innovation (FEI). New product ideas are often expected from customers even when consulted via crowdsourcing (noted in Soukhoroukova, Spann and Skiera, 2012; Poetz and Schreier, 2012; Magnusson, Wästlund and Netz, 2016; Hoornaert et al., 2017). It is possible to see the new product or new artifact idea as a complex entity that relates a solution to a problem. As a drawback seen in this process, we have the individual's dependence on the pre-existing technology knowledge for the OI phenomenon. Whether this individual is a customer,

(1) PPGEM - Post-graduate Programme in Mechanical and Materials Engineering, Federal University of Technology - Paraná - Curitiba - PR - Brazil

*Corresponding author: kampa@utfpr.edu.br 
entrepreneur, or product developer, a solution must emerge. This situation promotes a creative character to OI. Although the idea of a new product can also be an opportunity, the concept of opportunity is broader and allows assuming a perceptive character. Thus, identifying a new product development opportunity also includes understanding a potential problem that an individual or group of individuals has, and the readiness to take a solution in the form of a product (based on Stull, Myers, and Scott, 2008). While both are valid paths, based on the assumption that people experience more problems than they can solve, it is crucial to give attention to problems in new product OI.

How does one obtain these valuable problems? This question points to theories from different fields. It is known that, through the intuitive way, individuals are known to recognize opportunities accidentally mostly (serendipity, finding without seeking) or by some tacit scheme unknown to the external observer. This path, however, is linked to the individual's previous experience, depends on its continuous alertness while experiencing reality and, among other factors (George et al. 2016), exhibits a variable behavior over time. Through the systematic or artificial way (deliberate search), there is the prescription of an explicit scheme to be followed, which induces a discrete behavior that, when used, leads to potential success. The prospecting depends on the frequency performed. Therefore, a prescriptive approach that combines the advantages of these paths is considered favorable to the initial question. However, it is difficult for an entity outside the identifier to incorporate the tacit cognitive aspects from the intuitive way necessary to prescribe and explicit such a hybrid approach. There are few reports on experimentation and direct exploration of the phenomenon conducted by the identifiers or researchers themselves or both.

These facts contribute to the following general research question. What and how should the OI be done to better influence PDP success? Specifically, in the context of new product development and the perspective of opportunities as problems, how does intuitive OI occur? Thus, this study aims to direct explore the phenomenon of new product OI and to provide an internal perspective through descriptive research. This exploratory single-case path aims to contribute to the prescription of new OI models as well as to provide new research questions and explanatory hypotheses as objects of future confirmatory works conducted by the scientific community.

\section{Method}

This work is characterized as descriptive research and is an intermediate result of a comprehensive prescriptive study. It is aligned with the philosophical paradigm of pragmatic research and is adherent to the science of the artificial (or design science) concept. As a structural reference, the study adopted the DRM (Design Research Methodology) prescriptive methodology, proposed by Blessing and Chakrabarti (2009). DRM originated in 1991 (Blessing, Chakrabarti, and Wallace, 1992, and 1995) to the spectrum of research in projective activities.

The DRM divides into four main stages (Blessing and Chakrabarti, 2009): i/research clarification; ii/first descriptive study (DS-I); iii/ prescriptive study; iv/second descriptive study. The work evolves with the elaboration of Reference Models (RMs), with a descriptive aspect, and Impact Models (IMs), of prescriptive appeal. The DS-I guides this paper and comprises (Blessing and Chakrabarti, 2009): i/literature review; ii/research focus determination; iii/research plan development for DS-I; iv/preparation of empirical study; and v/explanation of overall conclusions.

The literature review comprised books and articles, and the keywords "opportunity recognition" or "opportunity identification" or "opportunity discovery" or "opportunity creation." It consulted the databases available through CAPES (Coordination for Improvement of Higher Level Personnel), especially the Web of Science ${ }^{\mathrm{Tx}}$, Scopus (Elsevier), and Scielo. It also included the main works identified in the Mendeley® platform. The focus was on the effective use of the papers that presented systematic or bibliometric reviews or both.

The research focus was on discovering what and how to trigger the intuitive search of opportunities. Accepting the influence factors pointed out by George et al. (2016), it was pre-defined special attention to four factors: i/alertness; ii/interaction with other people (social capital); iii/previous experience/learning of new experience; and $\mathrm{vi} /$ cognition/reflection, among other inferred factors from practice (post-defined).

The study plan, based on the DRM suggestions, was: i/single-case exploratory research (structured as outlined in Gil, 2009 and 2016); ii/exploratory documentary analysis of the records (as suggested in Creswell, 2010, and Gil, 2009). The study accepted the premise that the direct exploration of the OI mental manifestation would not allow observation without researcher participation as an object.

From this definition, the last two steps in the DS-I constitute the execution of the plan outlined previously. The suggested activities are (Blessing and Chakrabarti, 2009): i/data collection; ii/data processing; iii/ data analysis and interpretation; iv/verification of results; v/outline of conclusions; vi/initial reference model update; vii/determination of the subsequent empirical studies. The following sections detail these steps.

\section{Data collection}

The collection took place throughout 2590 days. The study recorded the intuitive OI events from the twenty-fourth of September 2011 (24/09/2011) to the twenty-seventh of February 2017 (27/10/2018). In a pilot attempt, the research relied on the participant observation method, but it interrupted or altered the phenomenon. Then, it was altered to the observing participant method to record the potential opportunities first. Once recorded, the next step included the observer's reflection/introspection and recording of the phenomenon that took place. According to Gil (2009), the researcher observed the records, in the historical development of the event or relationship, in the scheme of the places where they unfolded, what the researcher saw and heard, and what most impressed, pleased, or shocked.

\section{Data processing}

Data processing precedes analysis and involves transcription, tabulation, and organization (Blessing and Chakrabarti, 2009, p. 116). This 
study transcribed data at the source. First, it encoded the participant's data and his potential opportunities by the variables: i/new functionality; ii/new quality; iii/new customer; iv/new configuration/technology. The observer's data followed the codification concepts established by Gil (2009): i/acts; ii/activities; iii/meanings; iv/participation; v/ relationships; and vi/situations.

\section{Data analysis and interpretation}

The analysis and interpretation deal with the data summarization, organization, and presentation in a graphical and tabular way or a matrix form, in order to provide an overview of the data and a starting point for analysis (Blessing and Chakrabarti, 2009, p.121). Since a single case and the authors' perspective base this study, the results are therefore non-generalizable and mixed with their interpretation. Thus, the results section of this paper presents a summary of data on participant and observer's records, and the experience reports complement them with brief interpretations.

\section{Verification of results}

The verification involves making judgments about the evidence plausibility and credibility (Blessing and Chakrabarti, 2009, p.124). Since these results come from the author and his personal lived experience, this verification seeks to support the inferences outlined on the experience reports through secondary data. It is necessary to recognize that this knowledge construction process is not neutral, as it is not possible to eliminate the researcher's subjectivity when he proposes to study a reality of which he is part (Gil, 2016, p.12). Qualitative methods, as the oral history of life, sometimes imply the approval of what is textualized by those who told the story. In the present case, the participant's text attests to his interpretation of what he lived and understood from the acquired experience of the phenomenon in its analysis units.

\section{Drawing conclusions and reference model updating}

The conclusion explanation seeks an alignment of research questions with the empirical result (Blessing and Chakrabarti, 2009, p. 128). It is possible to delineate in three experience report sections, identified as perspectives for emphasizing the author's influence (presented in this document results after the data summary sections). Thus, this study discusses the influence factors in focus, presents the interpretation of the observed phenomenon (opportunity emergence and identification), and performs the reference model update (elaborated in the first stage of DRM, not presented in this paper).

\section{Results}

\section{Summary of the participant's recorded data}

The 137 records in the period involved 126 potential artifacts, 112 in hardware (88.9\%) and 14 in software (11.1\%), and 11 service records (disregarded in this research). Table 1 summarizes the potential opportunities.

Table 1. Summary of the participant/identifier's recorded data.

\begin{tabular}{c|c|c|c|c}
\hline Registers & New utilities & New qualities & $\begin{array}{c}\text { New } \\
\text { clients }\end{array}$ & $\begin{array}{c}\text { New } \\
\text { configurations }\end{array}$ \\
\hline 126 & 16 & 0 & 0 & 115 \\
\hline $100 \%$ & $12,7 \%$ & 0 & 0 & $87,3 \%$ \\
\hline
\end{tabular}

It is possible to observe that the phenomenon was triggered mainly by the consideration of solution ideas, with the use of new configurations or some technology, even without total clarity. It was possible to observe that problems immediately preceded or were incubated in previous events. They remained incubated until the point where the identifier was able to bring up a way to solve them. Thus, although recorded data described the problems, the main catalyst element of the record was the lucubration of the solution idea to the new or recurring problem situation.

From the total potential artifacts, $114(90.5 \%)$ are directly related to the identifier's demands or desires, with a potential third-party appeal. It is unknown if they were new to the world or just to the customer/identifier. There have been records of both potential artifacts to aid new purposes and those directly related to the elimination of existing artifact deficiencies, employed by the identifier for some prior purpose. It was also possible to perceive potential opportunities grouped by their similarity of application areas.

In order to test the hypothesis of specialization, this study used the eight categories of the International Patent Classification (IPC, WIPO, 2020). Figure 1 shows the classification of potential hardware opportunities according to IPC categories. Since the area on the right for a Chi-square distribution with seven degrees of freedom equal to 94.7 is less than 0.001 (Johnston, 2020), the hypothesis that data is evenly distributed across the eight categories is firmly rejected. It is possible to observe that the identifier has more contributions in categories A and G.

Figure 1. Potential hardware opportunities according to IPC categories.

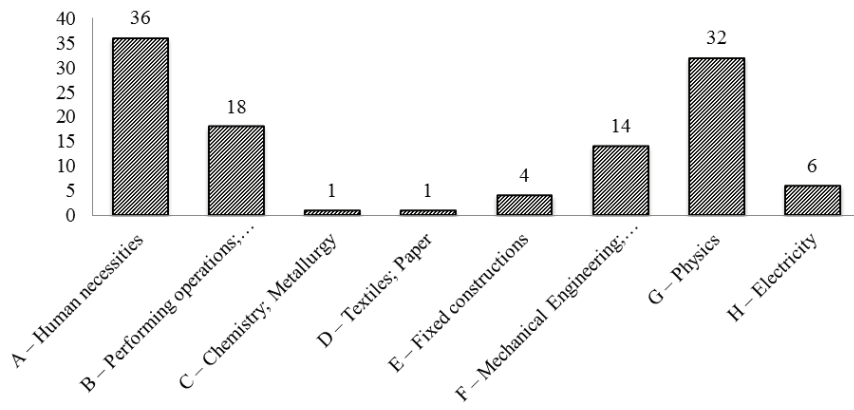

This summary brings new research questions about the reason for focusing on solutions rather than on the problems in the intuitive OI experienced. What is the reason for the incubation of problems experienced? How does one prevent a problem from being incubated, in order to anticipate OI for problems? How does one cease incubation in a previously incubated OI for problems? Does the intuitive OI tend to the identifier's demands or desires? Is the degree of ability to solve technical problems or prior experience by the IPC category related to the number of solutions found in the same categories? Does it differentiate the identifiers?

\section{Summary of observer's recorded data}

Placing the observer in the background implies post-fact introspection for recording and analysis. The study relies on the memories about the phenomenon, the documents generated, and the interpretation of what happened. 
Initially, the challenge was to try to separate and understand the behavior and thinking of the opportunity identifier (participant) and the observer personas. Though, it was possible to recognize the influence of an opportunity emergence persona into the identifier's character, performed by the participant and others. Table 2 shows the effort of summarizing the events perceived, remembered, and interpreted about the OI phenomenon, experienced in its 126 occurrences, through the codes of Gil (2009).

Table 2. Summary of perceived events on the OI phenomenon.

Acts: Actions developed in a temporally brief situation, consuming a few seconds, minutes or hours
Opportunity emergence: Unsuccessful use of prior artifacts to perform a task or part of it, with the experience of artifact deficiencies or inability to use it. Unsuccessful attempt to complete a task or part of it without the use of an artifact, with experience of self-limitations.

Opportunity identification: Act characterized by the instant reasoning of a new way of doing the task without the occurrence of the involved disorders, and related to a new artifact, changes in the previous artifact, or in the way of use or adaptation (actual changes). Search for improved artifacts for the task. Adaptation or disposal of other inappropriate artifacts. Reflection on the problematic situation experienced or imagined, personal or third parties. Conversation with third parties about a projected/imagined desired situation and what would be necessary to achieve success, as well as recapitulation and sharing of the experienced failures. Attempt to comfort third party complaints through known solutions or the creation of new ones.

Activities: Actions of longer duration (days, weeks, or months) that are significant elements of the individual's involvement.

Opportunity emergence: Similar to the acts, but with a longer duration, involving the conclusion of situations. With or without joint involvement of third parties.

Opportunity identification: Reflection on acts, activities, or problematic situations, imagined or experienced personally or by third parties, as well as the solutions employed or created.

Opportunity emergence: Suffering (shock) to fail in satisfactorily accomplishing the intent (situation, activity, or act). Which may be nonverbal or verbal, or both, in one's reflections or statements to others, seeking comfort or tolerance.

Meanings: Verbal and non-verbal products that define or direct actions

Opportunity identification: Mental insight and description of a potential technical configuration to assist an act of activity. A sensation of ecstasy (pleasure) to lucubrate or realize this insight (tachycardia, shiver, chill, relief). The consciousness of suffering visualized or declared by third parties (empathy, shock) due to the general failure of the satisfactory accomplishment of intent (situation, activity, or act).

The researcher performed the acts or activities in a situation of accomplishment of an objective or intent of personal or Participation: Global involvement or adaptation to a situation or studied position

third-party order (emergence).

The researcher observed third parties as performers of the acts or activities in a situation of achievement of purpose or intent. Also, he participated as a thinker of acts, activities, and post-fact situations, private or by third parties (identification).

Third parties perform acts, activities, or situations of accomplishment of their attempts, with or without success. Third parties declare problems and their suffering or boast of achieving success in their intended and employed means. Third parties share solutions.

Relationships: Relationships between individuals occurring simultaneously

The participant experienced the situation of attempting to perform an objective or intent or reflected on similar lived or imagined situations. It involves the identifier or third parties, with attention to their deliberate reports of these

Situations: The complete situation conceived within the study as a unit of analysis implying or not in adaptation requirements. The situation resulted in emotional, cognitive, or physical load, due to lack of knowledge or their usage, acquisition, or momentary access difficulties. Occurrences on participation, observation, or reflection on experiences of reality lived in the past, present, or imagined in the future. Also, in fictitious situations on those occasions, either personal or impersonal.

This summary raises new questions. Does the identifier only recognize in third parties the problems that these manifest in some way (verbal or nonverbal)? Does suffering precede the awareness of a problem or opportunity perception? Can the identifier only continually or immediately recognize the problems he/she experiences from his/ her suffering? Are there differences for OI in the context of a client identifier and a non-client identifier? How to reprogram emotional reactions to perceive the problems intuitively as opportunities?

\section{Perspective on the $\mathrm{OI}$ influence factors}

It is possible to observe that the influence factors reported by George et al. (2016) are interrelated. The experience contributed in a unique way to the interpretation of alertness.

This study sought to understand the state of alertness as the state of being in an instant preceding the perception or creation of potential: 
new functionality, new quality, new customer, and new configuration/ technology. It was possible to observe the occurrence of an emotional assault. The attention to the new solution resulted from a pleasurable emotional reaction (positive reaction to ideation or eureka) by mentally visualizing a solution without even having a consciously defined problem or the certainty of a reliable solution. While all the solution records resulted from problem situations immediately or previously experienced or imagined by the identifier, it is possible to induce that the unpleasant emotional assault of the problem situation led to its escape or its disregard. By not valuing them, the occurrences were incubated without, at first, being alert to them.

The incubation occurred without even saturation by attempting to solve the problem, which would be a conscious incubation, and unintentionally, as pointed out by Lumpkin and Lichtenstein (2005). The identifier on the situation sees no value in suffering or registering it. Problems reported by third parties were not so appealing to the identifier if he did not intend to find them (systematically). The report of people's suffering experiences in some problem situations also led the identifier, through empathy, to the problem incubation. Once more, the warning was deflagrated solutions imagined at the time of the reports or their subsequent reflection.

As for prior knowledge, the study sought to understand it as the problem/solution knowledge area: technologies (how), applications (what), users (who). It was possible to verify the relevance of the three axes related to previous knowledge, as pointed out by Shane (2000). The identifier has a specialization, and he was able to provide solutions to problems in areas of his knowledge. Without it, that would be no emotional reaction or warning to motivate the conscious registration. The trigger can also activate by conscious reflection on problem situations, a part of prior knowledge that, if not generated by himself/ herself in his/her experience, results from interacting with others to acquire it (directly or indirectly).

Regarding the cognition or processing or reflection factor for OI, this study sought to understand it as the questions/heuristics that accompany or precede the OI. It is possible to verify that the relative thought processes follow each case singularity and are not deliberate to OI (at the limit with a systematic search). There was a mental recapitulation about a situation experienced by himself or others, but organically, without the search intent. Moreover, as explained, once reflecting on the ideas that were the emotional trigger for the registration and initial attention, it was possible to reflect on their fundamental problems and start a process of problematization and ideation. Thus, it is possible to infer that thought or cognition processes involve memory processing and act as a catalyst for the transition from incubation to the "eureka" situation.

Concerning the factor interaction with other people, this study sought its presence or not before the finding of other factors. What is possible to observe is that not only conversations with third parties but also their subsequent recapitulation was stimulating to reflection, and this last one, to the trigger. In a way, third parties were sources of problems and solutions to be dealt with by thought processes. The knowledge employed by the identifier also presented the contribution of previously acquired third party knowledge.

\section{Perspective on the opportunities emergence}

In the works consulted on OI, opportunities arise from changes in environmental conditions, considered as external to individuals. If the problems of customers interested in acquiring solutions characterize potential opportunities, those customers are partly responsible for the emergence of the latter. However, both the customer and the opportunity identifier may carry these problems within themselves, and this influences what OI means.

At the opportunity emergence as a problem, there is the experience or simulation of an intention accomplishment. In pursuit of success, the individual's autonomous capacities for accomplishment are employed or are altered (especially amplified) by connecting with auxiliary artifacts, or products (Figure 2).

Figure 2. Artifact-Individual or Individual-Artifact Connection (AI/IA).

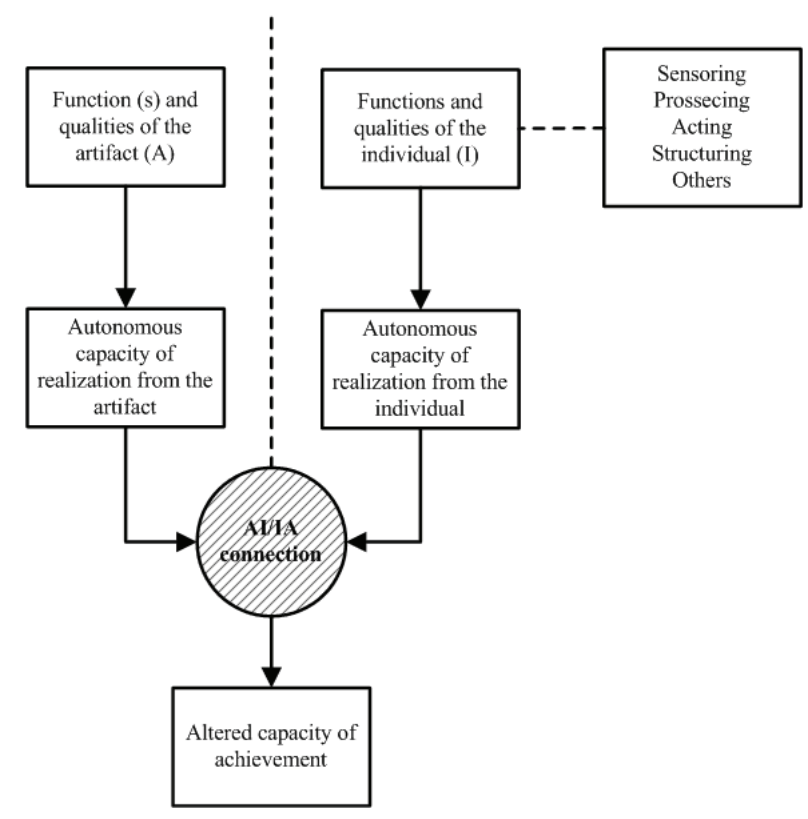

When not employing artifacts, the individual will engage the intent with their physical and cognitive abilities. He/she may be aware of his/her limitations, anticipate the transformation required of himself/herself, and look for artifacts to avoid or minimize the stress of changing. Thus, the presence or not of interaction with artifacts is crucial either for the resulting satisfaction or during realization. In the absence or non-proficiency of one or more artifacts to objectively or subjectively satisfy the individuals in their intent, there is a chance that the individual himself/herself or others will develop or enhance those artifacts.

These failures are evident between the expected and the obtained result of realization (even in the imagination), as disorders to the individual, in emotional reactions (suffering or discomfort). Nevertheless, 
even before they become aware, there is a natural tendency to escape, which leads to unconscious incubation of problems and, after some time, perhaps to the serendipity of some solution for the individual himself/herself (Figure 3). Even when conscious, the change may involve people and events outside the troubled individual's field, as the change of behavior in third parties.

Figure 3. Intuitive OI schema of the identifier-client or client-identifier (IC/CI).

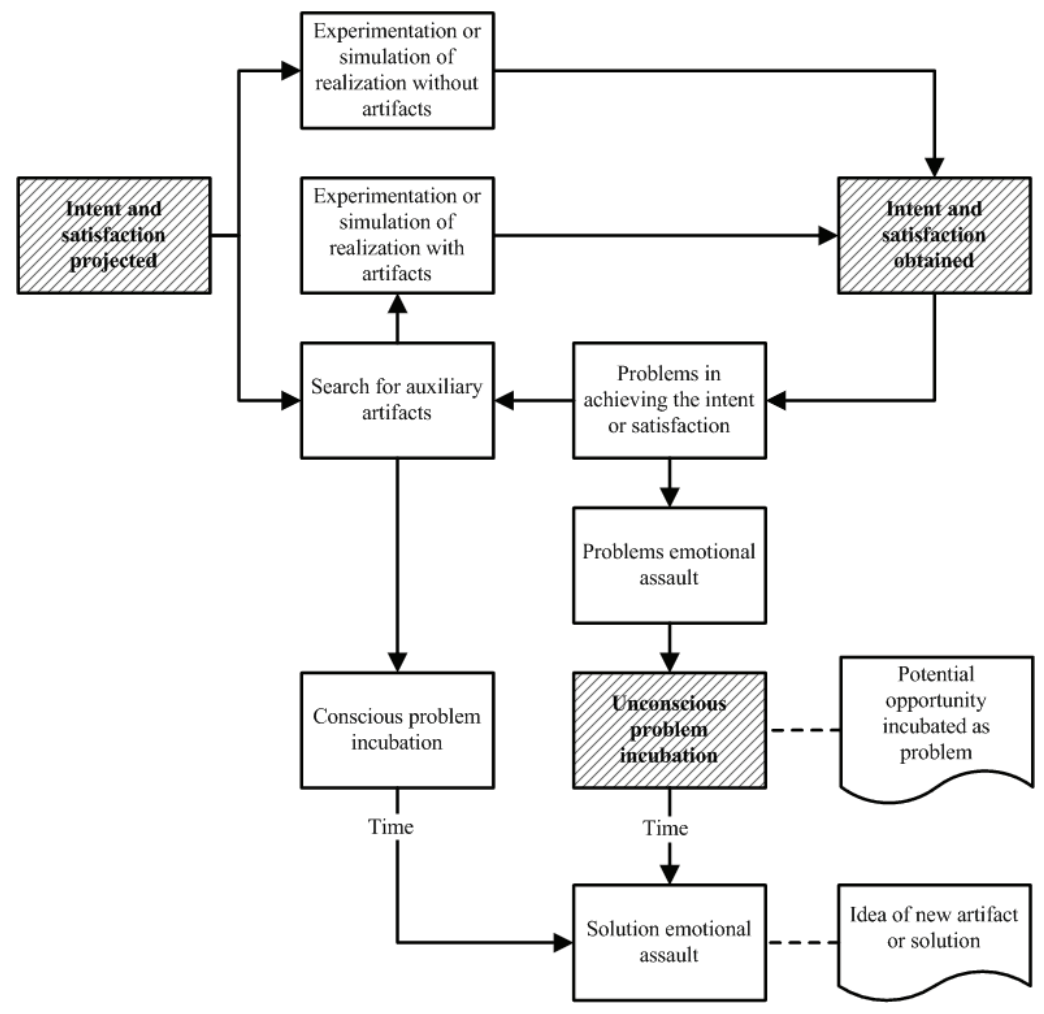

As a root of the problems that catalyze these emotions, it is possible to infer the individual's transformation demands to the intent (when artifacts do not exist, are unknown or inaccessible) or to artifacts employed (when inadequate). The transformation may require time, be unpleasant or uninteresting, as well as being desi- red and even constituting the purpose of the intent itself (learning a new game, accepting a challenge). The demands derive from the individual (who), the projected and obtained intent (what), and aid adopted (how). Figure 4 presents a reference model for the situation 
Figure 4. Opportunities emergence as problems reference model.

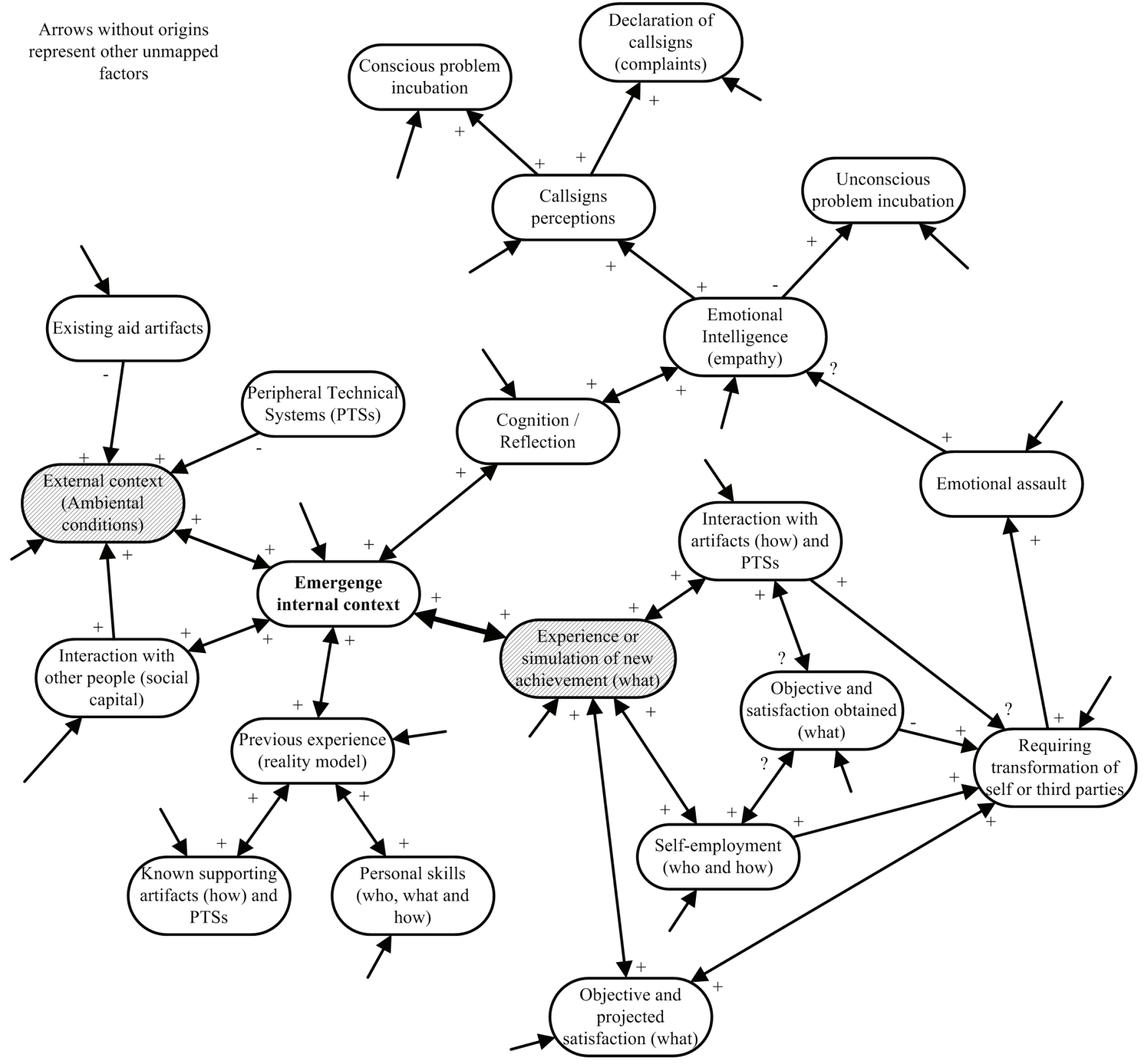

The study employed a terminology similar to the OI influence factors. It is necessary to interpret the model as an incomplete simplification of reality and start reading by the opportunity emergence internal context factor. This mental factor connects to all others (external context, interaction with others, previous experience, cognition, and the new experience or simulation of realization) and leads to the demands or desires to be fulfilled by new artifacts or products.

In the external context, there are, among others, the provision or not of artifacts and Peripheral Technical Systems (PTSs) to assist the client in specific realization experiences. External information also flows in this context, declared by third parties, and influencing the use or not of these artifacts and systems. These influence the definition and projected satisfaction of these achievement experiences. Thus, the internal context of emergence is also affected by its interaction with other individuals. These factors contribute to the formation of individuals' previous experience, which includes their abilities and knowledge of artifacts. These, in turn, can be employed to assist them in an experience or simulation of intent achievement in obtaining what they interpret as a success.

This experience or simulation starts from trying to achieve a goal and a projected satisfaction, which may be tacit or explicit. For this purpose, the individual's capabilities are used exclusively or in conjunction 
with that of auxiliary artifacts and PTSs. The individual exclusive selfemployment for the purpose may result in physical or mental distress and an unsatisfactory result. The path with the aid of previous artifacts follows a similar route, but with the potential additional stress of adapting the individual to the artifacts used. The result, as well as the internal or external obstacles (arrows without origin), reflect in the obtained satisfaction. If it falls short of the projected one, the result is to accept it or to remain dissatisfied. In short, there is exhaustion or emotional reactions to the problems faced to achieve the goal and the projected satisfaction. The emotional assault, if not understood by the individual's cognition, specifically by his Emotional Intelligence (EI), leads to two paths, among many others possible. Either unconsciously incubating the problem, or understanding the situation to the point of consciously declaring and internalizing it. This conscious incubation favors the commercialization of solutions. Thus, if the individual knows the problem, he can deliberately look for solutions, as well as he/she can be found by their offerings, which will make sense to him/ her.
In the situation lived, the identifier incubated problems while experiencing reality as a potential client of solutions. It is reasonable to say that it is possible only as a customer. The incubation, as well as the statement, occurs with those who suffer from the achievement experiences in their existence. Avoiding the concealment of problems requires a cognitive effort towards EI by those who suffer from them. Therefore, it is possible to conclude that, for the identifier to find opportunities for third party problems intuitively, the task becomes difficult due to the distance between the identifier and the constant reality of those whom he/she seeks to attend. Next, the study focuses on interpreting the experience as an opportunity identifier, with an appeal to himself/herself and third parties.

\section{Perspective on identifying opportunities}

From the introspection and interpretation of the phenomenon experienced, it is possible to observe a configuration of events over time, which affects both the emergence and the intuitive or automatic identification of opportunities as problems (Figure 5).

Figure 5. Scheme of emergence events and intuitive OI in the timeline.

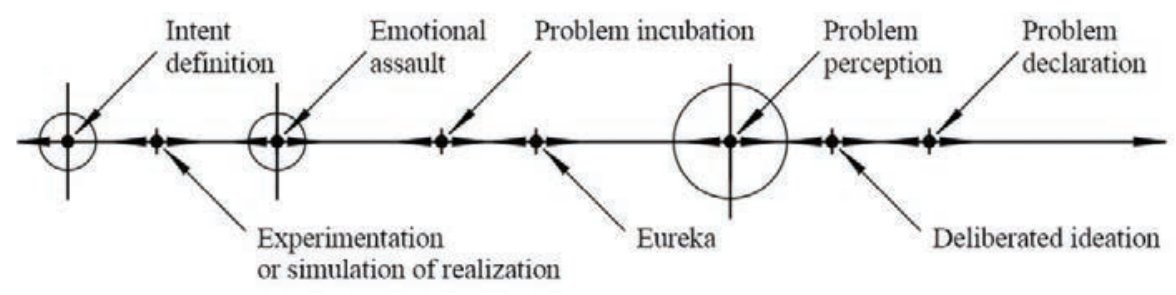

In this timeline, it is possible to highlight the point of intuitive OI, characterized by the problem perception. All points are moveable on the timeline, but the order in which they can alternate depends on their relationship. It is possible to interpret that, for the OI by problems, the moments or cases that initially precede it are three in the absence of the problem incubation or solution eureka: i/the definition of the intent to be achieved; ii/the experimentation or achievement simulation; iii/emotional assault during or after the achievement (experienced in real life or imagined). The problem perception can precede its conscious incubation or solution.

In the first moment, the originality of the intent itself may be the opportunity for the development of artifacts and products. When someone sets an intent, whether original or conventional, there is an opportunity for others to assist with the supply of artifacts. Original intentions differ from conventional ones because, at first, they may or may not have as much appeal to others. This situation is evident in new sports or games that create opportunities to exploit artifacts to others by defining new goals that gain their interest in achievement. Besides, it is possible to exploit their original defined intent if it is not yet well supplied by third parties or by customers. When someone makes product adaptations or combines multiple products in an even amateur mode, it indicates that he/she is trying something beyond the conventional. It is also interesting to observe that this attempt can be tacit and triggered by frustration or satisfaction.
In the second case, a step further, capable of revealing problems in the realization of the defined intent. It is where specific problems occur, with or without emotional appeal, because of processes themselves, either internally or by external influence (the environment and third parties). Individuals can perceive rational problems during the experiment without necessarily having an unconscious incubation. Whereas, if there are no rational solutions, the problem may or may not be consciously incubated. Also included here are those problems triggering conscious emotional reactions, such as physical injuries caused by some artifact or derived from the intent and applied autonomous capacities. It is possible to verify a conscious non-acceptance of a transformation in one's own body (cut, bruise, heat, among others), but it may also be associated with an unconscious non-acceptance (fury for being cut, shame for falling or sweating, among others).

The third case, however, refers to the common elements which hide from perception and moves toward unconscious incubation: the emotional hijack of the problems of accomplishing intent. If perception can be the awareness of the sense organs, it is possible to deduce that the alteration of these organs occurs before awareness. They can also be affected without any awareness of what happened. Therefore, it can be hidden from reason even if repeatedly experienced (as observed). If OI is a perception of a tacit or consciously explicit problem that competes with the incubation of the problem itself, the first sign of its presence would be this emotional reaction. If there is no 
discomfort with the problem, it may also not motivate the additional economic spending to eliminate it. There is a problem, but no potential opportunity.

In the recapitulation of the studied cases, it is essential to observe that the emotional reaction sometimes leads to an act of escape from the problem. There is a shortcut from the sensors to the action. This action depends on the difficulty that is present. According to the observed cases, actions came either instinctively or consciously to bypass a difficulty. They included: i/immediate abandonment of the intent; ii/change in the way of acting, iii/change in the artifact use; iv/search or exchange of artifact; v/situation acceptance and the gradual abandonment of the intent; vi/search of more information for success (interaction with third parties); vii/exacerbation at various levels; among other subtle reactions. In a way, the unconscious non-acceptance of particular demands of self-alteration imposed on realization (autonomous or aided by some artifact) caused these actions.

These observations refer to client-identifier or identifier-client situations, as experienced, although it is unclear whether the identifier could stop behaving as a customer. If, by employing so well the techniques of raising the customer's voice, he/she could internalize the customer's situation to the point of seeing himself/herself on the customer's position. If being able to find a chance of obtaining value by offering another, this offer may be valid for customers outside those where the identifier mirrors. Thus, it is possible to hypothesize that, for the intuitive OI as problems, it is favorable that the identifier approaches the emergence context of these problems, just as the client that the identifier aims to attend approaches. However, the identification of third party problems implies a discrete behavior over time because an individual can only maintain a continuous behavior being himself/herself, not pretending to be someone else. Thus, as the hypothesis evolves, to the intuitive OI as problems, in continuous or immediate mode, the identifier must be part of the emergence context of these problems and be affected by them. It is essential to experiment (or simulate) the achievement situation as a client of aid artifacts. Nonetheless, even in sporadically or continuously assuming the client's perspective, there could be conscious or unconscious problem incubation.

The unconscious problem incubation by their emotional assault is a critical factor to OI. In the observed cases, the identifier also registe- red problem situations, without presenting solution ideas for them. In a way, the identifier has managed to overcome its drawbacks and see the negative situation as potentially valuable. Somehow, there were re-association and valuation of these problems, inducing reflection some treatment of the emotions involved. Koçoğlua et al. (2015) point out the role of emotions since Hochschild's studies (1979) on emotional work, Salovey and Mayer (1990), and Goleman (1998) on EI, and Fineman (1993) on emotions in the context of organizations. Works related to emotions and some aspect of the OI spectrum also corroborate on their relevance, such the studies by Baron (2008), Grichnik, Smeja and Welpe (2010), Foo (2011), Welpe et al. (2012), Hayton and Cholakova (2012), Cardon et al. (2012), Oriarewo, Agbin and Zever (2014), Treffers et al. (2017), Michl et al. (2017), Khalid and Sekiguchi (2018).

Bernal (2018) comments that reason dominates emotion by logic: an emotion can only be eliminated by another emotion that is stronger and more powerful or incompatible or both. The reason serves to arouse emotions that are incompatible with the undesirable ones. However, emotions mobilize reason (ibidem) differently from one individual to another (Mayer, Salovey, and Caruso, 2008). According to Goleman (2001, p. 307), feelings precede thoughts, for the rational mind takes longer to register and react to facts than the emotional mind. However, there are also emotional reactions that are not so fast and that they come from a rational process of deliberate thinking. Empathy is developed by knowing how to name emotions. However, there are more subtleties of emotions than words to define them (ibidem).

From the above, emotional reactions are faster than rational ones. Therefore, OI, as a perception of a problem, arises after emotion. The latter precedes any problematization that may occur from it. The problematization, through EI, competes with the incubation. Therefore, the emotions expressed and the complaints are the first indications of problems that may arise and eventually report to or by third parties. Also, emotional reactions may be immediate or as a result of a deliberate thought process. Hence, one can have emotional responses both by experiencing reality and by reflecting on it. It is possible to deduce that reflection can reactivate certain emotions experienced and be employed to avoid or cease incubation in unconsciously or consciously incubated problems over time. Thus, the situation experienced by the identifier is partially modeled by the OI reference model in Figure 6, based on primary and secondary data. 
Figure 6. Opportunities identification reference model.

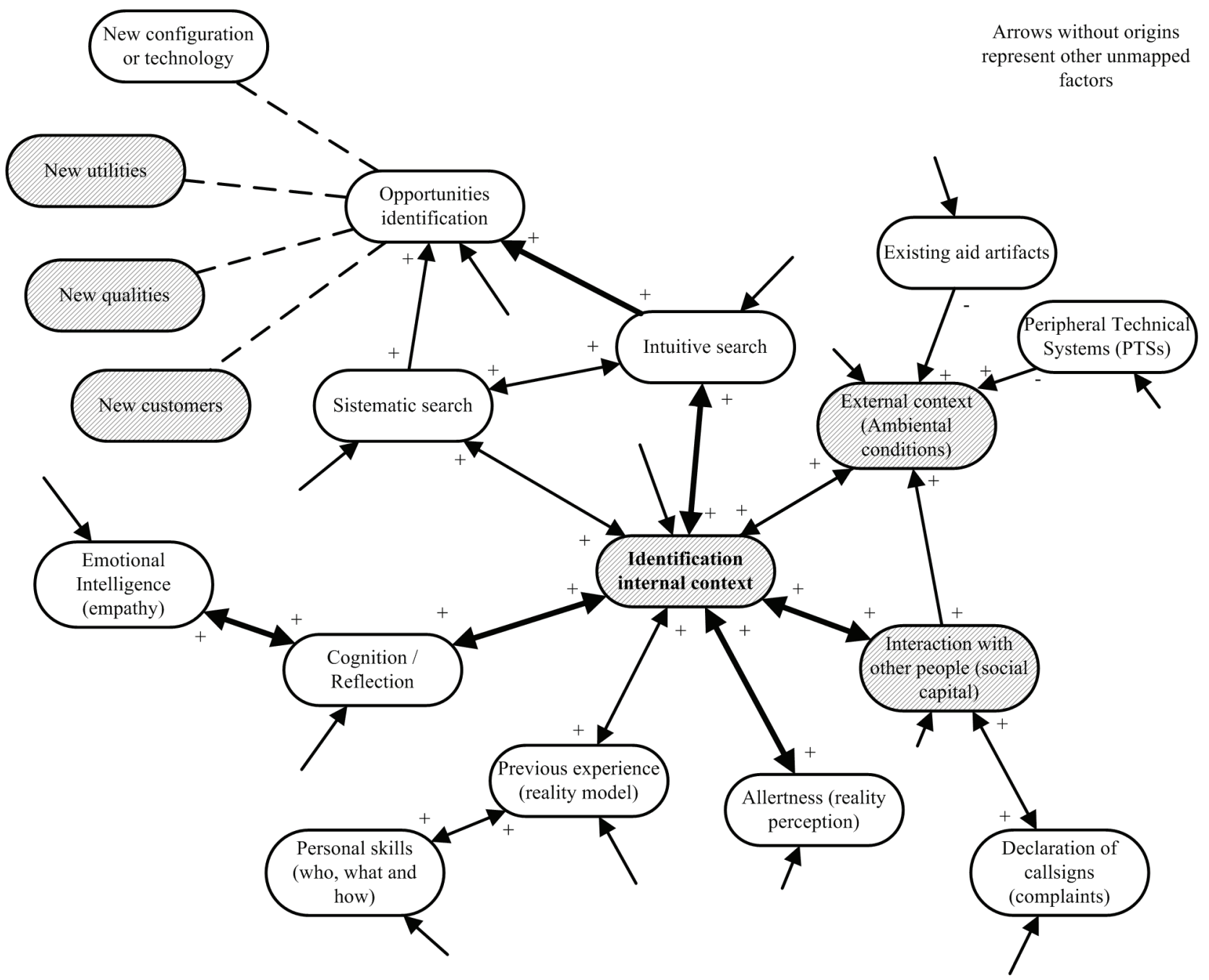

It is possible to notice that the factors pointed out by George et al. (2016) began to receive double meaning arrows in order to make explicit their interrelationship. For the identifier that does not pretend to be a customer or does not see himself/herself as a customer, he/ she will depend on the interaction with these customers. It implies that the clients declare opportunity traces or complaints (verbally or not). The artifacts the customer uses or not to reach a specific intent new to the world or not can influence the identifier. These artifacts are present in an external context to the identifier, and also influence customer's expectations associated with the achievement or simulation. The identifier still needs the EI associated with the cognition factor, so that, in this interaction with third parties, he/she can perceive or be alert to the value of their problems or be able, through his/her previous knowledge, to propose solutions of interest. The OI occurs because of these factors, which go through a deliberate or unintentional search process, in which the influence of one factor on the other cannot be wholly distinguished, but appears to be positive.

The unification of the opportunity identification reference model with the opportunity emergence reference model exposes the situation of the identifier-customer or customer-identifier. Figure 7 presents a simplified view of the connection between the models presented in Figure 5 and Figure 6 .

Figure 7. Simplified unified reference model of opportunities emergence and identification.

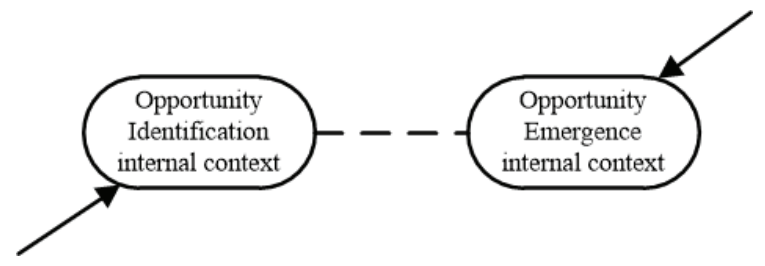


The models are unified by the internal context of opportunity emergence and by the internal context of opportunity identification, as being internal to the same person's mind are both connected. The arrows simplify and represent all the influence factors depicted in the previous reference models. Figure 8 provides the overall unified reference model.

Figure 8. Opportunities emergence and identification unified reference model.

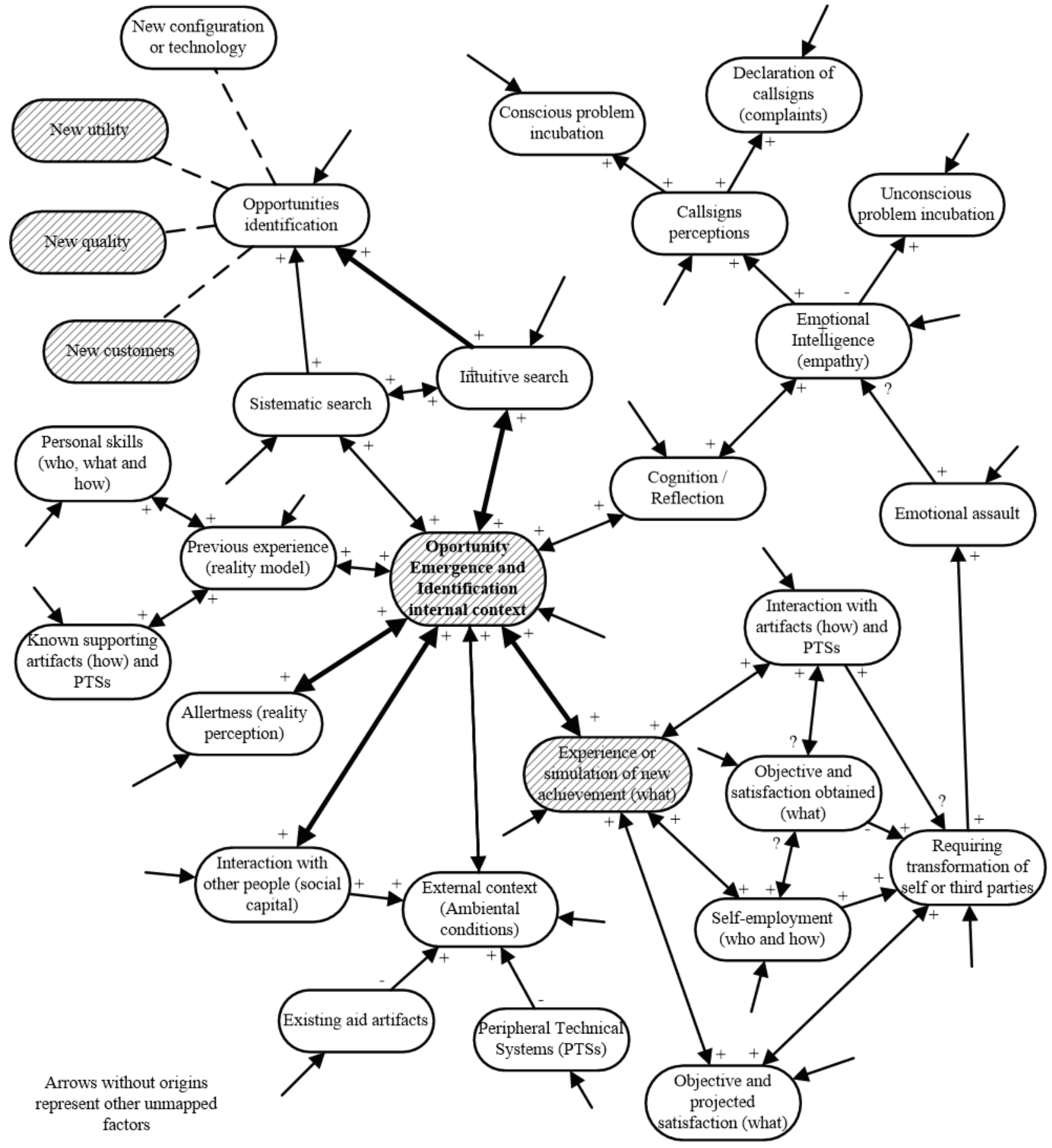

Considering the situation as inherent to a single individual, this presents an internal context that integrates the internal opportunity identification and opportunity emergence contexts. This way, the identifier experiences the reality of new achievement of intent or simulates it and is potentially affected by these process drawbacks. The identifier also depends on EI to avoid the problem incubation, or to modify the way of reflecting these experiences. Solution ideas can continue to evolve accordingly to the identifier's prior knowledge and 
creative capabilities. The differential of what the identifier perceives also depends on his agility about other individuals' external context, with which he may or may not interact. It also relies on what they are capable of declare or express.

\section{Discussion}

As this research provides an internal perspective to the phenomenon, these observations apply to the case as interpreted. They should not be taken as generalizations to a population without proper verification by statistical testing from these observations. The models presented are exploratory, relevant to the prescription by the DRM structure, and constitute a starting point to further researches.

Intuitively, the identifier of opportunities (as problems) will depend on perceiving his/her problems or those of others. The problem, if not stated by a third party or triggered by an observer of that third party, or of the observer himself/herself, can be hidden and ignored until one has an idea of a solution that triggers a noticeable positive emotional reaction.

Problems tend to provoke adverse or withdrawal emotional reactions. Once these reactions precede conscious and unconscious problem incubation, it is possible to infer that, in order to stimulate intuitive $\mathrm{OI}$ as problems, it is necessary to give conscious attention to emotional signs to prevent incubation from occurring. There is the challenge of finding problems hidden instinctively. Since perception is the awareness of the sense organs, to perceive problems as opportunities, the reason must reprogram emotional reactions. In order to prescribe an intuitive OI model, it is advisable to pay attention to what emotional intelligence presents. Reason can give new meaning to the emotions of detachment and frustration in the achievement experiences.

These experiences' pains are often not easily observed, and even if the client can explain them, this explanation will occur in a deliberate, non-intuitive search situation for the identifier. Thus, the identifier is more likely to perceive the pain of his/her achievement experience continuously or immediately. This discrete/continuous or series/parallel dichotomy becomes urgent to agile OI. When taken as a task, the OI enters serially in the individual's experience, because it takes the time that he/she could use with other activities and thoughts. When taken as a perspective or paradigm through which reality is observed and understood, it can transit together with the other activities lived in parallel, and which constitute his/her achievement experiences. What someone carries with oneself in these experiences are the faculties in an internal cognitive context. What can be drawn from experience is what can be grasped from reality. However, individuals do not live in a permanent state of reflection on their existence. It brings implications for OI and prescription aid models.

Finally, the authors recommend that potential opportunities, when recognized intuitively, be taken as hypotheses that start from a nonrepresentative sample of the population, as they rely on the context of the identifier's experience on a potential client projection.

\section{References}

Alvarez, S. A., Barney, J. B., Mcbride, R., \& Wuebker, R. (2017). On opportunities: philosophical and empirical implications. Academy of Management Review, 42(4), 726-730.

Ardichvili, A., Cardozo, R., \& Ray, S. (2003). A theory of entrepreneurial opportunity identification and development. Journal of Business Venturing, 18(1), 105-123.

Baron, R. A. (2008). The role of affect in the entrepreneurial process. Academy of Management Review, 33(2), 328-340.

Baron, R. A., \& Shane, S. A. (2007). Empreendedorismo: uma visão do processo. [Entrepreneurship: a view of the process]. São Paulo: Thomson Learning.

Berglund, H., \& Korsgaard, S. (2017). Opportunities, time, and mechanisms in entrepreneurship: on the practical irrelevance of propensities. Academy of Management Review, 42(4), 730-733.

Bernal, I. M. (2018, November 05). O que é (exatamente) a inteligência emocional? [What is (exactly) emotional intelligence?]. El País. Retrieved November 10, 2018, from https://brasil.elpais.com/brasil/2018/10/24/ciencia/1540372846_255478.html

Blessing, L. T. M., Chakrabarti, A., \& Wallace, K. (1992). Some issues in engineering design research. In: N. Cross (Ed.), OU/SERC Design Methods Workshop, The Open University, Milton Keynes.

Blessing, L. T. M., Chakrabarti, A., \& Wallace, K. (1995). A design research methodology. In: V. Hubka (Ed.), International Conference on Engineering Design (ICED'95) (pp. 502-507). Heurista, Zürich, Prague.

Blessing, L. T. M., \& Chakrabarti, A. (2009). DRM, a design research methodology. London: Springer.

Butler, J. E. (Ed.) (2004) Opportunity identification and entrepreneurial behavior. Greenwich: Information Age Publishing.

Cardon, M. S., Foo, M. D., Shepherd, D., \& Wiklund, J. (2012). Exploring the heart: Entrepreneurial emotion is a hot topic. Entrepreneurship Theory and Practice, 36(1), 1-10.

Cooper, R. G. (2001) Winning at new products: accelerating the process from idea to launch (3rd ed.). New York: Basic Books.

Cooper, R. G. (2017) Winning at new products: accelerating the process from idea to launch (5th ed.). New York: Basic Books.

Cooper, R. G., \& Edgett, S. J. (2007). Generating breakthrough new product ideas: feeding the innovation funnel. [S.I.], Canada: Product Development Institute.

Creswell, J. W. (2010). Projeto de pesquisa: métodos qualitativo, quantitativo e misto. [Research project: qualitative, quantitative and mixed methods]. (3rd ed.). Porto Alegre: Artmed. 
Davidsson P. (2017a). Entrepreneurial opportunities as propensities: Do Ramoglou \& Tsang move the field forward? Journal of Business Venturing Insights, 7, 82-85.

Davidsson P. (2017b). Reflections on misgivings about "dismantling" the opportunity construct. Journal of Business Venturing Insights, 7, 65-67.

Davidsson P. (2017c). Opportunities, propensities, and misgivings: some closing comments. Journal of Business Venturing Insights, 8, 123-124.

De Jong, J. P. J., \& Marsili, O. (2015). The distribution of Schumpeterian and Kirznerian opportunities. Small Business Economics, 44(1), 19-35.

Fiet, J. O. (2007). A prescriptive analysis of search and discovery. Journal of Management Studies, 44(4), 592-611.

Fiet, J. O., Clouse, V. G. H. \& Norton Junior, W. I. (2004). Systematic search by repeat entrepreneurs. In: J. E. Butler (Ed.), Opportunity identification and entrepreneurial behavior (pp. 1-27). Greenwich: Information Age Publishing.

Fineman, S. (1993). Organizations as emotional arenas. Thousand Oaks: Sage Publications.

Foo, M. D. (2011). Emotions and entrepreneurial opportunity evaluation. Entrepreneurship Theory and Practice, 35(2), 375-393.

Foss, N. J., \& Klein, P. G. (2017). Entrepreneurial discovery or creation? in search of the middle ground. Academy of Management Review, 42(4), 733-736.

George, N. M., Parida, V., Lahti, T., \& Wincent, J. (2016). A systematic literature review on entrepreneurial opportunity recognition: insights on influencing factors. International Entrepreneurship and Management Journal, 12(2), 309-350.

Gil, A. C. (2009). Estudo de caso. [Case study]. São Paulo: Atlas.

Gil, A. C. (2016). Como elaborar projetos de pesquisa. [How to design research projects]. (5th ed.). São Paulo: Atlas.

Goleman, D. (1998). Working with emotional intelligence. New York: Bantam.

Goleman, D. (2001) Inteligência emocional: a teoria revolucionária que redefine o que é ser inteligente. [Emotional intelligence: the revolutionary theory that redefines what it is to be intelligent]. Rio de Janeiro: Objetiva.

Grichnik, D., Smeja, A., \& Welpe, I. (2010). The importance of being emotional: how do emotions affect entrepreneurial opportunity evaluation and exploitation? Journal of Economic Behavior and Organization, 76(1), 15-29.

Hansen, D. J., Monlor, J., \& Shrader, R. C. (2016). Identifying the elements of entrepreneurial opportunity constructs: Recognizing what scholars are really examining. The International Journal of Entrepreneurship and Innovation, 17(4), 240-255.
Hayton, J. C., \& Cholakova, M. (2012). The role of affect in the creation and intentional pursuit of entrepreneurial ideas. Entrepreneurship Theory and Practice, 36(1), 41-68.

Hochschild, A. R. (1979). Emotion work, feeling rules, and social structure. American Journal of Sociology, 85(3),551-575.

Hoornaert, S., Ballings, M., Malthouse, E. C., \& Van Den Poel, D. (2017). Identifying new product ideas: waiting for the wisdom of the crowd or screening ideas in real time. Journal of Product Innovation Management, 34(5), 580-597.

Johnston, N. (n.d.). Chi-square distribution. Retrieved April 22, 2020, from http://www.statdistributions.com/chisquare?chi=94.7\&df=7

Kelley, T., \& Littman, J. (2007). As 10 faces da inovação: estratégias para turbinar a criatividade. [The ten faces of innovation: Ideo's strategies for beating the devil's advocate \& driving creativity throughout your organization]. Rio de Janeiro: Elsevier.

Khalid, S., \& Sekiguchi, T. (2018). The role of empathy in entrepreneurial opportunity recognition: An experimental study in Japan and Pakistan. Journal of Business Venturing Insights, 9, 1-9.

Kim, W. C., \& Mauborgne, R. (2015). Blue ocean strategy: how to create uncontested market space and make the competition irrelevant (Expanded ed.). Boston: Harvard Business Review Press.

Kim, W. C., \& Mauborgne, R. (2017). Blue ocean shift. New York: Hachette Book.

Kirzner, I. M. (1973). Competition and entrepreneurship. Chicago: University of Chicago Press.

Kitching, J., \& Rouse, J. (2017). Opportunity or dead end? Rethinking the study of entrepreneurial action without a concept of opportunity. International Small Business Journal: Researching Entrepreneurship, 35(5), 558-577.

Ko, S. (2004). Bisociation and opportunity. In: J. E. Butler (Ed.), Opportunity identification and entrepreneurial behavior (pp. 99-114). Greenwich: Information Age Publishing.

Koen, P. A., Ajamian, G. M., Boyce, S., Clamen, A., Fisher, E., Fountoulakis, S., Johnson, A., Puri, P., \& Seibert, R. (2002). Fuzzy front end: effective methods, tools, and techniques. In: P. Belliveau, A. Griffin, \& S. Somermeyer, (Eds.), The PDMA toolbook 1 for new product development (pp. 5-35). New York: John Wiley \& Sons Inc..

Koçoğlua, İ, Imamoğlub, S. Z., Akgünc, A. E., İnced, H.; \& Keskin, H. (2015). Exploring the unseen: a collective emotional framework in entrepreneurial orientation and business model innovation. Procedia - Social and Behavioral Sciences, 207(20), 729-738.

Lumpkin, G. T., \& Lichtenstein, B. B. (2005). The role of organizational learning in the opportunity recognition process. Entrepreneurship: Theory and Practice, 29(4), 451-472. 
Magnusson, P. R., Wästlund, E., \& Netz, J. (2016). Exploring users' appropriateness as a proxy for experts when screening new product/ service ideas. Journal of Product Innovation Management, 33(1), 4-18.

Mayer, J. D., Salovey, P., \& Caruso, D. R. (2008). Emotional intelligence new ability or eclectic traits? American Psychologist, 63(6), 503-517.

Michl, T., Welpe, I. M., Spörrle, M., \& Picot, A. (2017). The role of emotions and cognitions in entrepreneurial decision-making. In: M. Brännback, \& A. Carsrud (Eds.), Revisiting the entrepreneurial mind: Inside the black box: An expanded edition (International studies in entrepreneurship book 35) (pp. 219-242). Cham, Switzerland: Springer.

Oriarewo, G. O., Agbin, K. C., \& Zever, T. A. (2014). Relationship between emotional intelligence and entrepreneurial performance: the mediating effect of managerial competence. International Journal of Economics, Commerce and Management, 2(10), 1-16.

Poetz, M. K., \& Schreier, M. (2012). The value of crowdsourcing: can users really compete with professionals in generating new product ideas? Journal of Product Innovation Management, 29(2), 245-256.

Ramoglou, S., \& Tsang, E. W. K. (2016). A realist perspective of entrepreneurship: opportunities as propensities. Academy of Management Review, 41(3), 410-434.

Ramoglou, S., \& Tsang, E. W. K. (2017a). In defense of common sense in entrepreneurship theory: beyond philosophical extremities and linguistic abuses. Academy of Management Revie, 42(4), 736-744.

Ramoglou, S., \& Tsang, E. W. K. (2017b). Accepting the unknowables of entrepreneurship and overcoming philosophical obstacles to scientific progress. Journal of Business Venturing Insights, 8, 71-77.

Ramoglou, S., \& Zyglidopoulos, S. C. (2015). The constructivist view of entrepreneurial opportunities: a critical analysis. Small Business Economics, 43(1), 71-78.

Salovey, P., \& Mayer, J. D. (1990). Emotional intelligence. Imagination, Cognition, and Personality, 9, 185-211.

Schumpeter, J. A. (1934). The theory of economic development. Cambridge: Harvard University Press.

Schumpeter, J. A. (1942). Capitalism, socialism, and democracy. New York: Harper.
Shane, S. (2000). Prior knowledge and the discovery of entrepreneurial opportunities. Organization Science, 11(4), 448-469.

Shane, S., \& Venkataraman, S. (2000). The promise of entrepreneurship as a field of research. Academy of Management Review, 25(1), 217-226.

Soukhoroukova, A., Spann, M., \& Skiera, B. (2012). Sourcing, filtering, and evaluating new product ideas: an empirical exploration of the performance of idea markets. Journal of Product Innovation Management, 29(1), 100-112.

Stull, C., Myers, P., \& Scott, D. M. (2008). Tuned in: uncover the extraordinary opportunities that lead to business breakthroughs. New Jersey: John Wiley\& Sons, Inc..

Treffers, T., Welpe, I. M., Spörrle, M., \& Picot, A. O. (2017). The role of emotions and cognitions in the pre-entrepreneurial process: What's New? In: M. Brännback, \& A. Carsrud (Eds.), Revisiting the entrepreneurial mind: Inside the black box: An expanded edition (International studies in entrepreneurship book 35) (pp. 243-259). Cham, Switzerland: Springer.

Urban, G. L., \& Hauser, J. R. (1993). Design and marketing of new products. New Jersey: Prentice-Hall.

Vaghely, I., \& Julien, P. (2010). Are opportunities recognized or constructed? An information perspective on entrepreneurial opportunity identification. Journal of Business Venturing, 25(1), 73-86.

Welpe, I. M., Spörrle, M., Grichnik, D., Michl, T., \& Audretsch, D. B. (2012). Emotions and opportunities: the interplay of opportunity evaluation, fear, joy, and anger as antecedent of entrepreneurial exploitation. Entrepreneurship Theory and Practice, 36(1), 69-96.

WIPO (2020). International patent classification. Retrieved April 22, 2020, from https://www.wipo.int/classifications/ipc/ipcpub/?notion $=$ scheme\&version $=20200101 \&$ symbol=none\&menulang $=$ en $\&$ lang $=$ en $\&$ viewmode $=\mathrm{f} \& \mathrm{fip} \mathrm{cpc}=$ no\&showdeleted $=$ yes\&indexes $=$ no \&headi ngs $=$ yes $\&$ notes $=$ yes $\&$ direction $=02$ n \&initial $=A \& c w i d=$ none $\&$ tree $=n$ o\&searchmode $=$ smart

Wood, M. S. (2017a). Misgivings about dismantling the opportunity construct. Journal of Business Venturing Insights, 7, 21-25.

Wood, M. S. (2017b). Continued misgivings: a response to Davidsson on dismantling the opportunity construct. Journal of Business Venturing Insights, 7, 77-81. 
